\title{
Relationship between type A behavior patterns and risk of temporomandibular disorder in Japanese undergraduate students
}

\author{
Hiroki Ohmi ${ }^{1}$, Mariko Kato ${ }^{1}$ and Martin Meadows ${ }^{2}$ \\ ${ }^{1}$ Department of Nutritional Sciences, Faculty of Health and Welfare Science, Nayoro City University, Japan \\ ${ }^{2}$ Department of Liberal Arts Education, Faculty of Health and Welfare Science, Nayoro City University, Japan
}

\begin{abstract}
Objective: Several studies have demonstrated the relationship between temporomandibular disorder (TMD) and emotional stress. Nonetheless, few surveys have examined the relationship between type A behavior patterns and TMD. The aim of this study was to clarify the relationships among TMD, type A behavior patterns, bruxism, and emotional stress in Japanese undergraduate students.

Methods: This study was undertaken in Nayoro City, Japan, in 2015, among students of Nayoro City University. The survey was conducted through an anonymous, self-administered, multiplechoice questionnaire. Information was gathered on items evaluating the extent of TMD symptoms, bruxism, type A behavior patterns, and proneness and sensitivity to emotional stress.

Results: The questionnaire recovery rate was $31.8 \%(175 / 551)$. There was a high likelihood of TMD in $16.1 \%$ of respondents, which is comparable to the findings of previous surveys on Japanese high school students. In keeping with previous studies, we confirmed significant relationships between TMD and both emotional stress and bruxism. A weak but statistically significant association was found between TMD and type A behavior patterns.

Conclusion: We propose that TMD may be one of the diseases related to the type A behavior pattern.
\end{abstract}

Key words: temporomandibular disorder, type A behavior patterns, bruxism, emotional stress, undergraduate students

(J Rural Med 2016; 11(2): 77-80)

Received: March 3, 2016

Accepted: April 5, 2016

Correspondence: Hiroki Ohmi, Department of Nutritional Sciences, Faculty of Health and Welfare Science, Nayoro City University, W4N8 Nayoro, Hokkaido 096-8641, Japan

E-mail: hiohmi@nayoro.ac.jp

This is an open-access article distributed under the terms of the Creative Commons Attribution Non-Commercial No Derivatives (by-nc-nd) License $<$ http://creativecommons.org/licenses/by-nc-nd/4.0/>.

\section{Introduction}

Temporomandibular disorder (TMD) is defined as a noninflammatory disease characterized by the three major symptoms of pain and/or tenderness in the region of the muscles of mastication and the temporomandibular joint (TMJ), sounds during condylar movements, and limitation of mandibular movement. TMD more commonly affects adolescent women ${ }^{1-3)}$. The causal factors of TMD include psychological (proneness and sensitivity to emotional stress, behavior patterns, bruxism, etc.) as well as mechanical and functional problems of the $\mathrm{TMJ}^{2,3)}$. Several studies have demonstrated the relationships between TMD and both emotional stress and bruxism ${ }^{4-6)}$. The relationship between bruxism and emotional stress has also been investigated ${ }^{4-6}$. On the other hand, surveys examining the relationship between type A behavior patterns (TABP) and TMD are scarce $^{7}$. The aim of this study was to confirm the relationships among TMD, TABP, bruxism, and emotional stress in Japanese undergraduate students.

\section{Methods}

\section{Subjects}

In May 2015, Nayoro City University enrolled 551 undergraduate students from the first to third years of a four-year program (male: 88 , female: 463 ), all of whom participated in the survey. Students belonged to The Faculty of Health and Welfare Science or The Department of Early Childhood Education, and were aged 18 to 21 years.

\section{Data collection}

Data collection was conducted anonymously in May 2015 by means of a self-administered, multiple-choice questionnaire. In addition to gender, the questionnaire contained 
Table 1 Items for bruxism screening

\begin{tabular}{l}
\hline \multicolumn{1}{c}{ Items } \\
\hline Do you feel orofacial jaw muscle fatigue or pain on waking up? \\
Do you have cracked or ground teeth? \\
Do your upper and lower teeth touch when you shut your mouth? \\
Are you ever aware of involuntarily clenching your teeth during computer working or driving? \\
Do you have a bite scar or teeth imprints on the inner side of your cheek? \\
Are you chronically troubled with severe stiff shoulders? \\
Do you have a headache frequently? \\
Do you feel stiffness in the jaw frequently? \\
Do you experience soreness on your gums on consuming cold food?
\end{tabular}

There were four response alternatives, ranging from never to very often.

items concerning TMD, bruxism, TABP, and proneness and sensitivity to emotional stress. Items used to calculate the TMD score were taken from a questionnaire designed by Sugisaki et al.$^{8,9}$, which has been approved by The Japanese Society for the Temporomandibular Joint ${ }^{10}$. Items concerning bruxism consisted of nine items taken from questionnaires created by Kataoka et al. ${ }^{4)}$, Winocur et al. ${ }^{11)}$, and Tsukagoshi et al. ${ }^{12)}$ (Table 1), modified to fit the current study. Items for the TABP score came from the screening test developed by Hosaka et al. ${ }^{13}$. Accordingly, the respondents in the present study were categorized into the following ranks: A1: extreme TABP, A2: moderate TABP, B2: moderately opposite to TABP, and B1: extremely opposite to TABP. Levels of proneness and sensitivity to emotional stress were assessed based on the following two questions: "Do you feel emotional stress these days?" (proneness) and "To what extent does emotional stress affect your behavior, if at all?" (sensitivity). Responses were made on a 4-point Likert scale ranging from never to very often for the former question, and not at all to very much for the latter.

The protocol of this study was approved by the Ethics Committee of Nayoro City University.

\section{Statistical analysis}

Data were digitized and then analyzed with descriptive and non-parametric statistics in order to clarify the relationships among TMD, bruxism, TABP scores, and proneness and sensitivity to emotional stress. Statistical methods included a contingency table (the Fisher's exact test), rank testing (the Mann-Whitney U test and Kruskal-Wallis test followed by the Steel-Dwass test), and the Spearman's rank correlation coefficient analysis. All $P$-values were based on a two-tailed test and a significance level lower than 0.05 was considered as significant. Statistical analyses were performed using the IBM SPSS Statistics 19.0.0 and EZR 1.28 ${ }^{14)}$ statistical packages.
Table 2 Relationship among TMD, bruxism, and TABP score

\begin{tabular}{lccc}
\hline & & Bruxism score & TABP score \\
\hline TMD score & $\rho$ & 0.421 & 0.131 \\
& $P$ & $<0.001$ & $\mathrm{~ns}$ \\
& $\mathrm{n}$ & 172 & 173 \\
\hline Bruxism score & $\rho$ & & 0.213 \\
& $P$ & & 0.005 \\
& $\mathrm{n}$ & & 173 \\
\hline
\end{tabular}

$\rho:$ Spearman's rank correlation coefficient.

\section{Results}

\section{Prevalence of TMD}

Among the 551 subjects, valid responses from 175 students were obtained (recovery rate: $31.8 \%$ ). Among respondents, the prevalence of high likelihood of TMD was $16.1 \%$ (the TMD score was equal to or higher than nine).

\section{Relationship among TMD, emotional stress, bruxism, and} TABP

A high likelihood of TMD was correlated with sensitivity to emotional stress $(P<0.001$ : Fisher's exact test), but not to proneness. Students with a high likelihood of TMD had both higher bruxism scores $(P<0.001$ : Mann-Whitney $\mathrm{U}$ test) and TABP scores $(P=0.049$ : Mann-Whitney U test). To investigate the relationships among the TMD, bruxism, and TABP scores, the Spearman's rank correlation coefficients were examined (Table 2). The TMD and bruxism scores, and the bruxism and TABP scores were both found to have significant positive correlations. The TMD and TABP scores were not statistically correlated.

Students with resilience (lower sensitivity) to emotional stress had lower TMD $(P=0.049$ : Kruskal-Wallis test $)$ and bruxism scores $(P<0.001$ : Kruskal-Wallis test followed by Steel-Dwass test). Resilience to emotional stress was correlated with the TABP rank $(P=0.015$ : Fisher's exact test $)$. 


\section{Discussion}

\section{Main findings of this study}

According to previous surveys conducted on Japanese high school students, the prevalence of TMD was 10 to $\left.20 \%{ }^{15}, 16\right)$. These data were based on dental check-ups conducted at school, carried out by a dentist. Although this study estimated the likelihood of TMD through a questionnaire alone, the prevalence of TMD was comparable to that reported in previous studies. This may be due to the validity of the questionnaire items used to assess the TMD score, as confirmed by previous studies ${ }^{8,9)}$ and The Japanese Society for the Temporomandibular Joint ${ }^{10)}$.

This study also demonstrated the relationships between TMD and emotional stress, as well as between TMD and bruxism $^{4-6)}$. The relationships between bruxism and emotional stress, and bruxism and TABP were also investigated $^{4-6)}$. In 1974, Friedman and Rosenman proposed that TABP was an independent risk for coronary heart disease ${ }^{17)}$. Recently, several diseases (arteriosclerosis ${ }^{18)}$, ventricular hypertrophy $^{19)}$, atrial fibrillation ${ }^{20)}$, metabolic syndrome ${ }^{21)}$, hypercholesterolemia ${ }^{22)}$, open-angle chronic glaucoma ${ }^{23)}$, cerebral infarction ${ }^{24)}$, dementia ${ }^{25)}$, burnout syndrome ${ }^{26)}$ ) have been found to be associated with TABP. However, surveys on the relationship between TABP and TMD are rare ${ }^{7}$. In the present study, a weak but statistically significant association was found between TMD and TABP; a similar result was reported ${ }^{7}$. Thus, it is proposed that TMD may be one of the TABP-related diseases.

\section{Limitations of this study}

This study was conducted in a small university with a small sample. The relationship between the TMD and TABP score could not be confirmed by calculating the Spearman's rank correlation coefficients, mainly because of the small sample size and low questionnaire recovery rate. To elucidate a direct correlation between TMD and TABP score, studies need to be conducted on a larger sample.

\section{Conclusion}

To clarify the relationships among TMD, TABP, bruxism, and emotional stress, a questionnaire survey was conducted with Japanese undergraduate students. A weak but statistically significant association was confirmed between TMD and TABP. It is proposed that TMD may be one of the TABP-related diseases.

Conflict of interest: The authors declare that they have nothing to declare.

\section{References}

1. Funakoshi M. The physiology of temporomandibular joint dysfunction. J Acad Clin Dentist 1984; 5: 11-15 (in Japanese).

2. Nakayama R, Nishiyama A, Kino K, et al. Influence of contributing factors in temporomandibular disorders in female college students. Kokubyo Gakkai Zasshi 2013; 80: 62-67 (in Japanese). [Medline]

3. Oral K, Bal Küçük B, Ebeoğlu B, et al. Etiology of temporomandibular disorder pain. Agri 2009; 21: 89-94. [Medline]

4. Kataoka K, Ekuni D, Mizutani S, et al. Association between self-reported bruxism and malocclusion in university students: a cross-sectional study. J Epidemiol 2015; 25: 423430. [Medline] [CrossRef]

5. Imamura H, Kanemura K, Tanabe N, et al. Relationship between consciousness of bruxism and temporomandibular disorders in dental students. Ann Jpn Prosthodont Soc 2011; 3: 353-359 (in Japanese). [CrossRef]

6. Ahlberg J, Rantala M, Savolainen A, et al. Reported bruxism and stress experience. Community Dent Oral Epidemiol 2002; 30: 405-408. [Medline] [CrossRef]

7. Pingitore G, Chrobak V, Petrie J. The social and psychologic factors of bruxism. J Prosthet Dent 1991; 65: 443-446. [Medline] [CrossRef]

8. Sugisaki M, Kuruma E, Kino K, et al. Selection and validity test of one question item for screening of temporomandibular disorders. J Jp Soc TMJ 2007; 19: 233-239 (in Japanese).

9. Sugisaki M, Takano N, Kino K, et al. Prevalence of temporomandibular disorders among working population of Tokyo. J Jp Soc TMJ 2008; 20: 127-133 (in Japanese).

10. The Japanese Society for the Temporomandibular Joint What temporomandibular disorder is? http://kokuhoken.net/jstmj/ general/ [accessed: February 2016].

11. Winocur E, Uziel N, Lisha T, et al. Self-reported bruxism - associations with perceived stress, motivation for control, dental anxiety and gagging. J Oral Rehabil 2011; 38: 3-11. [Medline] [CrossRef]

12. Tsukagoshi K, Nishiyama A, Kino K, et al. The factor which affects temporomandibular disorder-related pain. J J Orofacial Pain 2011; 4: 45-55 (in Japanese).

13. Hosaka T, Tagawa R, Hinohara S, et al. Association of screening test for type A behavior pattern at the health counselling center. JMHTS 1989; 16: 32-37. [CrossRef]

14. Kanda Y. Investigation of the freely available easy-to-use software 'EZR' for medical statistics. Bone Marrow Transplant 2013; 48: 452-458. [Medline] [CrossRef]

15. Ohno H, Morinushi T, Horikawa $\mathrm{S}$, et al. An epidemiological study of TMJ dysfunction syndrome in adolescents - prevalence and distribution of the symptoms of TMJ dysfunction syndrome. Shoni Shikagaku Zasshi 1985; 23: 94-102 (in Japanese). [Medline]

16. Mogi E, Yamaguchi H. Review of temporomandibular joint disease (TMD) 8. TM joint disorder in young age. Shikagakuhou 2002; 103: 211-222 (in Japanese). 
17. Friedman M, Rosenman R. Type A Behavior and Your Heart. Knopf, New York, 1974

18. Liu H, Saijo Y, Zhang X, et al. Impact of type A behavior on brachial-ankle pulse wave velocity in Japanese. Tohoku J Exp Med 2006; 209: 15-21. [Medline] [CrossRef]

19. Munakata M, Hiraizumi T, Nunokawa T, et al. Type A behavior is associated with an increased risk of left ventricular hypertrophy in male patients with essential hypertension. J Hypertens 1999; 17: 115-120. [Medline] [CrossRef]

20. Eaker ED, Sullivan LM, Kelly-Hayes M, et al. Anger and hostility predict the development of atrial fibrillation in men in the Framingham Offspring Study. Circulation 2004; 109: 1267-1271. [Medline] [CrossRef]

21. Ravaja N, Keltikangas-Järvinen L, Viikari J. Type A behavior and metabolic syndrome precursors in young adults. J Clin Epidemiol 1996; 49: 335-343. [Medline] [CrossRef]

22. Shizuka K, Yambe T, Fukudo S, et al. Type A behaviour pattern and hypercholesterolemia in elder patients. Nippon Ronen Igakkai Zasshi Japanese Journal of Geriatrics 2000; 37: 486-489 (in Japanese). [Medline] [CrossRef]

23. Bubella RM, Bubella DM, Cillino S. Type A behavior pattern: is it a risk factor for open-angle chronic glaucoma? J Glaucoma 2014; 23: 199-201. [Medline] [CrossRef]

24. Kim JS, Yoon SS, Lee SI, et al. Type A behavior and stroke: high tenseness dimension may be a risk factor for cerebral infarction. Eur Neurol 1998; 39: 168-173. [Medline] [CrossRef]

25. Bokenberger K, Pedersen NL, Gatz M, et al. The type A behavior pattern and cardiovascular disease as predictors of dementia. Health Psychol 2014; 33: 1593-1601. [Medline] [CrossRef]

26. Lavanco G. Burnout syndrome and type A behavior in nurses and teachers in Sicily. Psychol Rep 1997; 81: 523-528. [Medline] [CrossRef] 